\title{
HPA-axis genes as potential risk variants for neurocognitive decline in trauma-exposed, HIV-positive females
}

This article was published in the following Dove Press journal:

Neuropsychiatric Disease and Treatment

\author{
Sean Jacobs \\ Karis Moxley \\ Jacqueline SWomersley \\ Georgina Spies \\ Sian MJ Hemmings \\ Soraya Seedat
}

Department of Psychiatry, Faculty of Medicine and Health Sciences, Stellenbosch University, Cape Town, South Africa
Correspondence: Soraya Seedat Department of Psychiatry, Faculty of Medicine and Health Sciences, Stellenbosch University, PO Box 24I, Cape Town, 8000 South Africa

Tel +27219389227

Fax +27 219389738

Email sseedat@sun.ac.za
Purpose: Previous studies have independently provided evidence for the effects of HIV infection, hypothalamic-pituitary-adrenal (HPA) axis dysfunction and early life trauma on neurocognitive impairment (NCI). This study examined the interaction between single-nucleotide polymorphisms (SNPs) of two HPA axis genes, corticotrophin-releasing hormone receptor 1 (CRHR1; rs110402, rs242924, rs7209436, and rs4792888) and corticotrophin-releasing hormone-binding protein (CRHBP; rs32897, rs10062367, and rs1053989), childhood trauma, and HIV-associated NCI.

Patients and methods: The sample comprised 128 HIV-positive Xhosa females of whom $88(69 \%)$ had a history of childhood trauma. NCI was assessed using a battery of 17 measures sensitive to the effects of HIV, and the history of childhood trauma was assessed using the validated retrospective Childhood Trauma Questionnaire-Short Form. Generalized linear regression models were used to compare allelic distribution by trauma status and global NCI. The association between genotype, childhood trauma, and cognitive scores was also evaluated using generalized linear regression models, assuming additive models for the SNPs, and ANOVA.

Results: Of the seven polymorphisms assessed, only the rs10062367 variant of $C R H B P$ was significantly associated with global NCI $(P=0.034)$, independent of childhood trauma. This polymorphism was not significantly associated with $z$-scores on any specific cognitive domain. The interaction of childhood trauma and variants of CRHR 1 was associated with poorer learning (rs110402) and/or recall (rs110402 and rs4792888).

Conclusion: These findings suggest that $C R H B P$ rs $10062367 \mathrm{~A}$ allele is a possible risk variant for NCI in HIV, independent of childhood trauma. Furthermore, results show that the interaction of childhood trauma with variants of CRHR1, rs110402 and rs4792888, confer added vulnerability to NCI in HIV-infected individuals in cognitive domains that are known to be impacted by HIV. While these findings need independent replication in larger samples, it adds CRHBP and CRHR1 to the list of known genes linked to HIV- and childhood trauma-associated neurocognitive phenotypes.

Keywords: neurocognitive impairment, HIV, childhood trauma, HPA-axis, CRHBP, CRHRI

\section{Introduction}

In South Africa, the number of people living with HIV is estimated to be about 7.06 million (which is $12.6 \%$ of the total population) and includes more than one-fifth of all women aged 15-49 years. ${ }^{1}$ South African women are disproportionately affected by $\mathrm{HIV}$, and many also have trajectories characterized by trauma over the life course..$^{2-5}$ Trauma has been associated with impaired neurocognitive functioning, as well as 
the development of various psychopathologies, including major depressive disorder (MDD) and posttraumatic stress disorder. ${ }^{5,6}$ The effects of early life trauma may exacerbate the neurocognitive deficits caused by HIV infection.

HIV infection is associated with neurological and neurocognitive complications, collectively referred to as HIV-associated neurocognitive disorders (HAND). HAND describes a spectrum of disorders ranging from asymptomatic neurocognitive impairment (ANI), an intermediate form termed mild neurocognitive disorder (MND), to a severe form which constitutes HIV-associated dementia (HAD). ${ }^{7}$ The precise pathophysiology of neurocognitive impairment (NCI) in HIV-positive patients is not entirely clear, although it appears that only certain subsets of neurons and subpopulations of patients appear to be affected by HIV-induced central nervous system (CNS) injury, and both host and viral factors are important. ${ }^{8}$

The development of HAND negatively impacts social and occupational functioning, quality of life, and medication adherence. ${ }^{9,10}$ However, since the introduction of highly active antiretroviral therapy (HAART), the pattern of HAND appears to have radically changed. In particular, there has been a significant reduction in HAD with an increased prevalence of ANI and MND. ${ }^{7}$ Although less devastating than HAD, milder forms of HAND adversely impact important outcomes, including medication adherence and performance of cognitively demanding activities of daily living. ${ }^{11,12}$ It is still unclear why NCI persists in the post combined antiretroviral therapy (cART) era. Possible reasons include cardiovascular disease risk factors, ${ }^{13}$ immune system activation and inflammation, ${ }^{14-16}$ genetic factors, ${ }^{8,17}$ antiretroviral therapy neurotoxicity, ${ }^{18}$ substance abuse, ${ }^{19}$ advancing age, ${ }^{20} \mathrm{HIV}$ reservoirs within the $\mathrm{CNS},{ }^{21}$ and chronic dysfunction of the hypothalamic-pituitary-adrenal (HPA) axis. ${ }^{22}$

The HPA axis is the primary regulator of environmental stress in humans. Stress triggers the release of corticotrophinreleasing hormone $(\mathrm{CRH})$ which activates the HPA axis by binding to the corticotrophin-releasing hormone receptor 1 (CRHR1) in the anterior pituitary. The resultant neuroendocrine cascade culminates in the production of cortisol, which mediates the restoration of homeostasis. ${ }^{23}$ Aberrant HPA axis regulation has been associated with hippocampal atrophy, cognitive deficits, and a number of psychiatric disorders. ${ }^{24-26}$ HPA axis dysregulation occurs during the course of HIV infection due to a chronic increase in basal endogenous cortisol levels. ${ }^{22,27-29}$ Other possible mechanisms by which HIV may cause HPA axis dysfunction include chronic stress, ${ }^{30,31}$ direct CNS invasion and damage, secondary effects of cytokines, and side effects of antiretroviral therapy. ${ }^{32,33}$

Chronic dysregulation of the HPA axis has also been noted in several stress-related psychiatric disorders, especially in individuals traumatized in childhood. ${ }^{34-37}$ Therefore, early life trauma might, via its effect on the HPA axis, exacerbate NCI in HIV-positive patients. However, as genetic factors also play a significant role in the development of psychopathology following trauma exposure, ${ }^{38}$ examining genetic influences on this susceptibility may aid in identifying individuals most vulnerable to HAND and facilitate more targeted therapeutic and preventive interventions.

Genetic polymorphisms that could affect the function of genes known to regulate the HPA axis are considered likely determinants of the link between stress responsivity and risk for psychopathology. ${ }^{39}$ One way in which the HPA axis is regulated is by the CRH-binding protein (CRHBP), which binds CRH with high affinity making it unavailable for binding with the CRH type 1 receptor (CRHR1). ${ }^{40}$ CRHR 1 and CRHBP gene variants have been associated with a number of clinical phenotypes, including $\mathrm{MDD}^{41}$ and behavioral inhibition. ${ }^{42}$ Bradley et al also showed that two CRHR1 single-nucleotide polymorphisms (SNPs; rs1 10402 and rs7209436) interacted with childhood maltreatment to predict depressive symptoms in adulthood. ${ }^{43}$ In each case, maltreatment was associated with increased depression in carriers of a common allele ( $G$ for rs110402 and $C$ for rs7209436), while carriers of the rare allele ( $A$ for rs 110402 and $T$ for rs7209436) showed no increase in depressive symptoms compared to controls. Similarly, variations in three CRHBP SNPs (rs6453267, rs7728378, and rs10474485) may predispose to suicidal behavior in individuals who have experienced childhood trauma. ${ }^{44}$ Polymorphisms of genes in the CRH system have been associated with glucocorticoid resistance and reduced negative feedback of the HPA axis, ${ }^{45}$ as well as cortisol reactivity. ${ }^{46}$

In summary, genetic factors, childhood trauma, and HPA axis dysfunction might all be pathognomonic mechanisms and potentially interact in the development of psychopathology in individuals with HIV. To the best of our knowledge, no previous study has investigated the combination of these factors as possible determinants in the development of HAND. Spies et al previously reported on the independent and additive effects of HIV and early trauma in South African women. ${ }^{47}$ Therefore, using data from this same cohort, the aim of the current study was to assess the relationship between polymorphic variants in CRHR1 and CRHBP, childhood trauma, and the 
development of HAND in South African women diagnosed with HIV.

\section{Patients and methods Study design}

This study involved analysis of data from participants recruited as part of the Biological Endophenotypes of HIV and Childhood Trauma (BEHCT) study conducted at Stellenbosch University, Cape Town. The aim of the BEHCT study was to assess the genetic, cognitive, and neuroimaging outcomes in HIV-positive women. This study utilizes an adult female cohort (18-65 years), recruited between 2008 and 2013, with samples genotyped in 2017. The study design, data collection methods, and the inclusion/exclusion criteria for the BEHCT study have been described previously. ${ }^{27}$ The main procedures applicable to the current study are briefly outlined below.

\section{Study sample}

Out of 140 eligible women, 12 (9\%) were excluded from this study as genotyping data for these participants were not available. Therefore, a total of 128 HIV-positive, Black African Xhosa women who had full genetic and neurocognitive data were included in the present study. This particular demographic was chosen to reduce genetic heterogeneity. Eligibility criteria included willingness and ability to provide written informed consent, ability to read and write in either English or isiXhosa at fifth-grade level, aged between 18 and 65 years, and medically well enough to undergo neuropsychological testing. Exclusion criteria comprised a current or past history of schizophrenia, bipolar disorder, or other psychotic disorders; current substance or alcohol abuse or dependence; significant previous head injury; demonstrated frank dementia on the HIV dementia scale; current seizure disorders of any cause; history of CNS infections or neoplasms; hepatitis B-positive status; and current use within the last month of any psychotropic medication.

\section{Demographic, clinical, and psychological characteristics}

Age, gender, marital status, ethnicity, years of education, and employment status were captured by questionnaires, while virologic markers of HIV infection (CD4 lymphocyte counts) were obtained from blood samples. Current and lifetime psychiatric disorders were evaluated using the MINI International Neuropsychiatric Interview-Plus (MINI-Plus). ${ }^{48}$ Depressive and trauma symptomatology were assessed using the Center for Epidemiologic Studies Depression Scale (CES-D) and the Davidson Trauma Scale, respectively. ${ }^{49,50}$

\section{Childhood trauma and neurocognitive assessment}

Histories of abuse and neglect were assessed using the Childhood Trauma Questionnaire-Short Form (CTQ-SF), a 28-item self-report inventory that provides valid screening for histories of abuse and neglect. ${ }^{51}$ The tool assesses five types of maltreatment including emotional, physical, and sexual abuse and emotional and physical neglect. Each of these five subscales consists of five items, each of which is scored from 5 to 25 . Therefore, the total score ranges from 25 to 125 and higher scores reflect higher levels of childhood trauma. In particular, 25-31 = no trauma, $41-51=$ low-to moderate, $56-68=$ moderate-to-severe, and 73-125 = severeto-extreme. Similar to Spies et al, ${ }^{47}$ we used a score $\geq 41$ to identify trauma-exposed individuals, as this represents the lowest level score indicative of abuse or neglect (ie, low to moderate) for each subscale.

NCI was assessed using a battery of 17 tests that are sensitive to the effects of HIV infection. This battery was originally developed by the HIV Neurobehavioral Research Center at the University of California, San Diego, and has been culturally adapted for the South African context, as described by Spies et al. ${ }^{52}$ Childhood trauma and neurocognitive assessments were performed by trained researchers and were conducted in either English or isiXhosa.

\section{Genotyping}

DNA was extracted from whole blood using phenolchloroform extraction. Genotyping was conducted by LGC Genomics (United Kingdom). Validated SNPs with a minor allele frequency of $>0.2$ in at least one African population genotyped for the Hapmap project (www.hapmap.org), and which have been previously associated with some aspects of neuro-psychopathology, were selected for investigation. ${ }^{43,44,53}$ We genotyped four CRHR1 SNPs (CRHR1; rs110402 ( $C$ to $T$ ) [n=127], rs242924 ( $C$ to $A)$ [n=127], rs7209436 ( $C$ to $T)$ [n=122], and rs4792888 ( $G$ to $A)$ [n=122]) and three $C R H B P$ SNPs $(C R H B P$; rs32897 ( $G$ to $A)[\mathrm{n}=122]$, rs $1053989(C$ to $A)$ [n=126], and rs10062367 ( $G$ to $A$ ) [n=124]). Pair-wise linkage disequilibrium (LD) for the SNPs (Figure 1) was estimated using the solid spline method in Haploview, version $4 .{ }^{54}$ All genetic variants were in Hardy-Weinberg equilibrium $(P>0.05)$. 


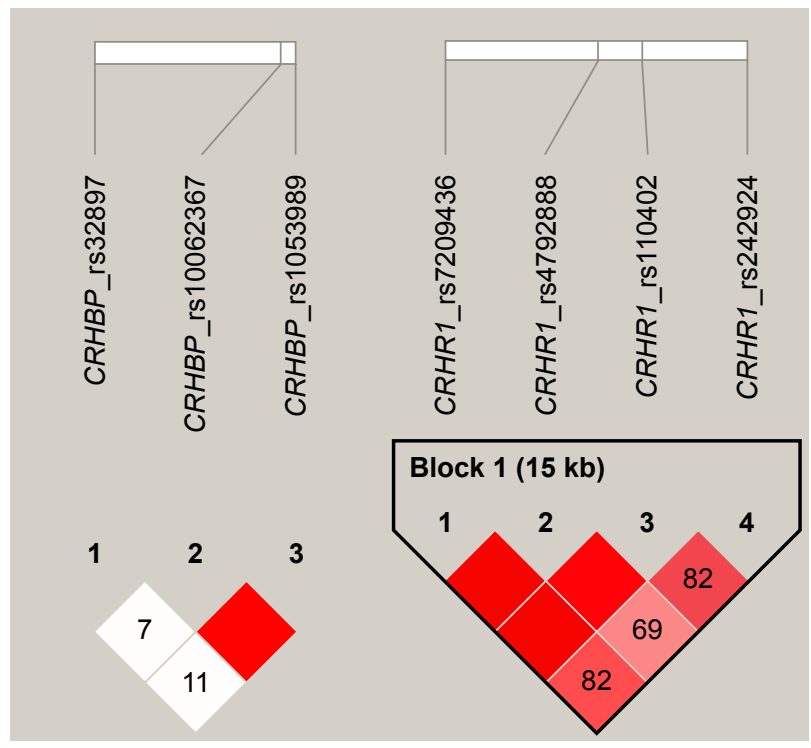

Figure I Haplotype block structure for CRHBP and CRHRI.

Note: The numbers in the squares refer to pairwise linkage disequilibrium (LD) measured as $\mathrm{D}$, with darker colors depicting stronger LD.

\section{Data analysis}

Demographic and clinical characteristics of study participants were summarized as counts and percentages for dichotomous traits, and means and SD or medians and 25th-75th percentiles (interquartile range) for quantitative traits.

Age- and education-corrected z-scores were calculated from all raw neuropsychological data and grouped into domains (motor function, verbal fluency, attention/working memory, speed, learning, recall, and executive functions). This was done by running a regression analysis on all raw neuropsychological data using test scores as the outcome and age and education as predictors. The residual was then saved, and a studentized residual was calculated. Within each domain, the studentized residual for each test was summed to obtain a domain $z$-score. Global NCI scores represent the mean of individual cognitive domain scores.

The Shapiro-Wilk W test was used to test for normality. Differences in normally distributed demographic and clinical variables (age, global NCI scores, NCI domain scores for verbal fluency, attention/working memory, speed, learning, recall, and executive functions) according to trauma status were determined using Student's $t$-test, while differences in non-parametric variables (CTQ scores, CES-D scores, viral load, CD4 counts, and NCI domain scores for motor function) were determined using Welch's unequal variances $t$-test. Pearson's chi-squared test was used to assess the relationship between categorical variables.
The contribution of each SNP to global NCI scores was evaluated using generalized linear regression models. When the results were significant, additional generalized linear regression models were used to evaluate the contribution of the SNP to individual cognitive domain scores. Generalized linear models, assuming additive models for the SNPs, were also used to evaluate if there was any association between genotype and CTQ scores, as well as to investigate the relationships between genotype, childhood trauma, and cognitive scores. Finally, analysis of variance (ANOVA) was used to determine whether including the interaction between genotype $\times$ childhood trauma explained more of the variance in cognitive domain scores than these two predictors acting individually. Antiretroviral (ARV) treatment and CES-D scores were included as covariates in the regression models.

Analyses were carried out using R statistical software version 3.2.2 (The R Foundation for Statistical Computing, Vienna, Austria) with the R package SNPassoc. ${ }^{55}$ Statistical significance was set at $P<0.05$.

\section{Ethical considerations}

The study was approved by the Health Research Ethics Committee (HREC \# N07/07/153A) of Stellenbosch University (Cape Town, South Africa). All participants gave written informed consent for participation according to locally and internationally accepted ethical guidelines. Participation in the present study was entirely voluntary and participants were informed of their right to withdraw their participation at any point in the study. Women who required further care were referred to their local community health care facility. Participants were reimbursed for their transport costs to attend study visits.

\section{Results}

Table 1 shows demographic and clinical variables for the overall sample and by trauma status. Of the 128 participants, 88 (69\%) had a history of childhood trauma. Those participants with childhood trauma had higher self-reported depression on the CES-D. This converged with interviewer-based assessment of psychopathology using the MINI-Plus, with a significantly greater proportion in the childhood trauma-exposed group meeting diagnostic criteria for recurrent MDD.

Less than half the sample (41.4\%) were on ARVs. ARV status had no significant impact on cognitive domain scores, except for the recall domain (Table 2).

Regression analysis revealed that individuals carrying at least one $C R H B P$ rs $10062367 G$ allele had significantly higher global NCI $z$-scores compared to subjects homozygous 
Table I Demographic and clinical characteristics of study participants $(n=128)$ showing differences between those with/without childhood trauma exposure

\begin{tabular}{|c|c|c|c|c|c|c|}
\hline \multirow[t]{2}{*}{ Variable } & \multirow[t]{2}{*}{ Overall $(n=\mid 28)$} & \multicolumn{5}{|c|}{ Childhood trauma exposure } \\
\hline & & No $(n=40)$ & Yes $(n=88)$ & $T$ & $\chi^{2}$ & $P$-value \\
\hline Mean age in years (SD) & $33.2(6.8)$ & $32.0(6.8)$ & $33.7(6.8)$ & -1.33 & - & 0.19 \\
\hline Mean years of education (SD) & $10.1(1.7)$ & $10.5(1.3)$ & $10.0(1.8)$ & 1.70 & & 0.09 \\
\hline \multicolumn{7}{|l|}{ Marital status, n (\%) } \\
\hline Single/separate & $102(79.7)$ & $30(29.4)$ & $72(70.6)$ & - & 0.790 & 0.48 \\
\hline Married/cohabiting & $26(20.3)$ & $10(38.5)$ & $16(61.5)$ & & & \\
\hline Unemployed & $85(66.4)$ & $24(60.0)$ & $61(69.3)$ & & 1.070 & 0.32 \\
\hline Median CD4 T lymphocyte count (IQR) & $396.0(237.8-587.5)$ & $347.0(195.3-587.5)$ & $416.0(259.5-604.8)$ & -0.94 & - & 0.35 \\
\hline On ARVs, n (\%) & $58(4 \mid .4)$ & $14(3 \mid .1)$ & $4 \mid(46.3)$ & - & 1.508 & 0.25 \\
\hline Median CTQ-SF (IQR) & $53.0(37.5-70.5)$ & $325.5(29-36)$ & $61.5(53-77.75)$ & -18.09 & - & $<0.01$ \\
\hline Depression (MDD, single), n (\%) & $6(5)$ & $0(0)$ & $6(7)$ & & & 0.09 \\
\hline Depression (MDD, recurrent), n (\%) & $9(7)$ & $0(0)$ & $9(10)$ & & & $0.04 *$ \\
\hline Median CES-D total score (IQR) & $8.5(0-27)$ & $4(0-11.75)$ & $14(0-48.1)$ & -3.70 & - & $<0.01$ \\
\hline
\end{tabular}

Notes: *Indicates a significant chi-squared or $t$-test at $P<0.05$.

Abbreviations: ARV, antiretroviral; CD4, cluster of differentiation 4 glycoprotein; CES-D, Center for Epidemiologic Studies Depression Scale; CTQ-SF, Childhood Trauma Questionnaire - short form; MDD, major depressive disorder, single or recurrent episode; IQR, interquartile range.

for the $A$ allele (Table 3). On further analysis, this polymorphism was not significantly associated with $z$-scores on specific cognitive domains.

There were no significant differences in childhood trauma CTQ-SF scores across genotypes. In addition, childhood trauma status was not significantly associated with global NCI ( $P=0.441$ ) or specific domain scores (motor function: $P=0.089$, verbal fluency: $P=0.894$, attention/working memory: $P=0.458$, processing speed: $P=0.430$, learning: $P=0.785$, recall: $P=0.238$, executive function: $P=0.996$ ). However, cognitive domain $z$-scores were influenced by the interaction between childhood trauma and polymorphisms in CRHR1. In particular, the presence of at least one $T$ allele in CRHR 1 rs110402 interacted with childhood trauma to worsen learning and recall. In contrast, the presence of at least one $C$ allele in CRHRI rs7209436 interacted with childhood trauma to improve learning and recall. Finally, the presence of at least one $A$ allele in rs4792888 interacted with childhood trauma to worsen recall (Table 4).

\section{Discussion}

We evaluated the interaction between childhood trauma, variants of two HPA-axis genes, $C R H B P$ and $C R H R 1$, and NCI in a sample of Black African Xhosa women living with HIV. Of the seven polymorphisms assessed, only the rs10062367 variant of $C R H B P$ was significantly associated with NCI, independent of childhood trauma. Compared to carriers of the rs $10062367 G$ allele, $A$ homozygotes had significantly lower global NCI scores. However, this polymorphism was not significantly associated with $z$-scores on specific cognitive domains. Host genetic factors have been found to predispose HIV-infected individuals to NCI. ${ }^{56,57}$ To the best of our knowledge, CRHBP rs10062367 has not been previously studied in the context of HAND. Therefore,

Table 2 Differences in mean global $\mathrm{NCl}$ scores (z-scores) by ART status

\begin{tabular}{|c|c|c|c|c|c|}
\hline \multirow{2}{*}{$\begin{array}{l}\text { Neurocognitive } \\
\text { domain }\end{array}$} & \multicolumn{2}{|c|}{ Mean NCl z-scores $( \pm \mathrm{SD})$} & \multirow[t]{2}{*}{$T$ value } & \multirow[t]{2}{*}{$d f$} & \multirow[t]{2}{*}{$P$-value } \\
\hline & ARVs & No ARVs & & & \\
\hline Motor $^{a}$ & $-0.159(1.500)$ & $0.097(0.700)$ & -1.170 & 69.8 & 0.246 \\
\hline Verbal fluency & $-0.101(0.802)$ & $-0.204(0.761)$ & 0.743 & 126 & 0.459 \\
\hline Working memory & $-0.067(0.735)$ & $-0.090(0.959)$ & 0.143 & 126 & 0.886 \\
\hline Speed & $-0.076(0.73 I)$ & $-0.018(0.679)$ & -0.463 & 126 & 0.644 \\
\hline Learning & $-0.172(0.870)$ & $0.067(0.827)$ & -1.578 & 126 & 0.117 \\
\hline Recall & $-0.235(0.938)$ & $0.063(0.733)$ & -2.017 & 126 & $0.046 *$ \\
\hline Executive functions & $-0.157(0.827)$ & $0.078(0.546)$ & -1.934 & 126 & 0.055 \\
\hline Global & $-0.125(0.577)$ & $-0.01 \mathrm{I}(0.533)$ & -1.157 & 126 & 0.250 \\
\hline
\end{tabular}

Notes: a Not normally distributed. Median scores (IQR) for this domain: Not on ART $=0.24 \mathrm{I}(-0.284$ to 0.550$)$; participants on ARV $=0.278$ ( -0.425 to 0.702$)$. *Indicates a significant $t$-test at $P<0.05$.

Abbreviations: ART, antiretroviral therapy; ARV, antiretroviral; IQR, interquartile range; $\mathrm{NCl}$, neurocognitive impairment. 
Table 3 Differences in neurocognitive impairment (z-scores) across genotypes for CRHBP rs 10062367

\begin{tabular}{llll}
\hline Genotype & $\begin{array}{l}\text { Frequency, } \\
\text { n (\%) }\end{array}$ & \multicolumn{2}{c}{ Neurocognitive impairment } \\
\cline { 4 - 4 } $\begin{array}{lll}\text { Zodominant } \\
\text { G/G }\end{array}$ & $40(32.26)$ & 0.0055 I $( \pm 0.592)$ & 0.106 \\
G/A & $57(45.97)$ & $-0.00474( \pm 0.554)$ & \\
A/A & $27(21.77)$ & $-0.25484( \pm 0.454)$ & \\
$\begin{array}{l}\text { Dominant } \\
\text { G/G }\end{array}$ & $40(32.26)$ & $0.00551( \pm 0.592)$ & 0.396 \\
G/A-A/A & $84(67.74)$ & $-0.08513( \pm 0.534)$ & \\
Recessive & & & $0.034^{*}$ \\
G/G-G/A & $97(78.23)$ & $-0.00052( \pm 0.567)$ & \\
A/A & $24(19.35)$ & $-0.25484( \pm 0.454)$ & \\
Additive & & & 0.080 \\
\hline
\end{tabular}

Note: *Indicates statistical significance at $P<0.05$.

our findings, while requiring further independent replication in a larger sample, may be the first to suggest a possible link between rs10062367 and NCI in HIV-infected individuals.

The lack of an association between NCI and other variants of $C R H B P$ suggest an independent effect of rs 10062367 on global neurocognitive deficits, or the effect of another polymorphism in LD with rs10062367. Other plausible reasons for the lack of a significant association between other SNPs and NCI may be the limited number of CRHBP polymorphisms that we assessed and the relatively small sample of HIV-infected participants.

In the current study, the interaction of childhood trauma and CRHR1 variants was associated with poorer learning (rs110402) and/or recall (rs110402 and rs4792888). Earlylife trauma has been associated with impaired neurocognitive functioning, ${ }^{6,47}$ and previous studies have demonstrated an association between childhood trauma and polymorphisms in CRHR1 and CRHBP in non-HIV samples. ${ }^{43,44}$ There may be a few reasons why trauma did not interact with $C R H B P$ gene variants in contributing to NCI in HIV-infected individuals. Firstly, the rs 10062367 CRHBP variant might confer vulnerability to NCI independent of environmental stress exposure, at least in this population. Various CRHBP polymorphisms have previously been associated with psychopathology including suicidality and anxiety, ${ }^{44,58-61}$ with emerging evidence also indicating that variants of the CRHBP gene (eg, rs28365143) can robustly predict pharmacotherapy outcomes in depression (ie, symptom change, response, and remission). ${ }^{61,62}$ Nevertheless, results show that the interaction of childhood trauma with variants of CRHR1, specifically rs 110402 and rs4792888, confer added vulnerability to neurocognitive decline in HIV-infected individuals.

A possible limitation of this study was that childhood trauma was assessed retrospectively and is, as such, prone to recall bias. Moreover, there are potential confounding variables which we did not control for, namely, 1) the possible trauma of contracting HIV and/or an effect of HIV infection overriding any effect(s) of childhood trauma, 2) any effect(s) of adult-onset trauma, 3) viral load and ARV regimen differences between the groups (there were, however, no significant differences in CD4 count between trauma exposed and unexposed groups), and 4) the higher level of self-reported depression in the childhood trauma group. Another limitation is that our sample included only Black African women living with HIV and we, therefore, cannot generalize our findings to HIV-uninfected individuals, other races or ethnic groups, or to HIV-infected males. Finally, this was a relatively small sample, and larger sample replication studies would be helpful to validate these findings.

Table 4 Predictive value of $C R H R I$ variants $\times$ childhood trauma interactions on cognitive domain scores

\begin{tabular}{|c|c|c|c|c|c|}
\hline Interaction & $d f$ & Deviance residual & df residual & Deviance & $P\left(>\chi^{2}\right)$ \\
\hline \multicolumn{6}{|l|}{ Learning } \\
\hline rsII0402+ CTQ & 122 & 88.690 & & & \\
\hline rs II $0402+$ CTQ + rs I I0402*CTQ & 121 & 85.212 & I & 3.478 & 0.03 \\
\hline rs7209436 + CTQ & 123 & 88.864 & & & \\
\hline rs7209436 + CTQ + rs7209436*CTQ & 122 & 85.502 & I & 3.362 & 0.03 \\
\hline \multicolumn{6}{|l|}{ Recall } \\
\hline rs II $0402+$ CTQ & 122 & 84.998 & & & \\
\hline rs II $0402+$ CTQ + rs I I0402*CTQ & $12 \mid$ & 79.703 & I & 5.295 & 0.01 \\
\hline rs7209436 + CTQ & 123 & 85.273 & & & \\
\hline rs7209436 + CTQ + rs7209436*CTQ & 122 & 80.158 & I & 5.114 & 0.01 \\
\hline rs4792888 + CTQ & 123 & 85.943 & & & \\
\hline rs4792888 + CTQ + rs4792888*CTQ & 122 & 82.918 & I & 3.025 & 0.04 \\
\hline
\end{tabular}

Abbreviation: CTQ, Childhood Trauma Questionnaire. 
Future studies should ideally include data from HIVnegative controls (unexposed to either child or adult trauma) and consist of larger sample sizes. There is also a need to investigate the functional effects these particular $C R H 1$ and $C R H B P$ SNPs. Moreover, to further interrogate the $C R H B P$ rs10062367 genotype and stress response abnormalities, future studies could investigate HPA-axis neuroendocrine endophenotypes of NCI (eg, cortisol). Future studies should also take duration ${ }^{63}$ and type $\mathrm{e}^{53}$ of trauma into account as these trauma variables can impact NCI.

\section{Conclusion}

The study shows that HPA-axis genes are possible risk variants for NCI among HIV-infected women and may interact with childhood trauma to impact specific domains of cognitive function. The combination of these vulnerabilities might be early markers of NCI in HIV-infected individuals and might represent potential targets for therapeutic action. However, replication studies involving whole gene-based association analyses of SNPs in CRHBP, as well as a more detailed analysis of childhood trauma, are needed.

\section{Acknowledgments}

We acknowledge the assistance from Michael McCaul (Center for Evidence-based Health Care, Stellenbosch University) and Muiruri Macharia (Department of Psychiatry, Stellenbosch University).

\section{Author contributions}

All authors contributed toward data analysis, drafting and critically revising the paper, gave final approval of the version to be published, and agree to be accountable for all aspects of the work.

\section{Disclosure}

The authors report no conflicts of interest in this work.

\section{References}

1. Statistics South Africa. Midyear population statistics. 2017. Available from: http://www.statssa.gov.za/publications/P0302/P03022017.pdf. Accessed May 31, 2018.

2. Andersson N, Cockcroft A, Shea B. Gender-based violence and HIV: relevance for HIV prevention in hyperendemic countries of southern Africa. AIDS. 2008;22(Suppl 4):S73-S86.

3. Jewkes R, Penn-Kekana L, Levin J, Ratsaka M, Schrieber M. Prevalence of emotional, physical and sexual abuse of women in three South African provinces. S Afr Med J. 2001;91(5):421-428.

4. Kalichman SC, Simbayi LC. Sexual assault history and risks for sexually transmitted infections among women in an African township in Cape Town, South Africa. AIDS Care. 2004;16(6):681-689.

5. Seedat $\mathrm{S}$. Interventions to improve psychological functioning and health outcomes of HIV-infected individuals with a history of trauma or PTSD. Curr HIV/AIDS Rep. 2012;9(4):344-350.
6. Spies G, Afifi TO, Archibald SL, Fennema-Notestine C, Sareen J, Seedat S. Mental health outcomes in HIV and childhood maltreatment: a systematic review. Syst Rev. 2012;1(1):1-30.

7. Heaton RK, Franklin DR, Ellis RJ, et al. HIV-associated neurocognitive disorders before and during the era of combination antiretroviral therapy: differences in rates, nature, and predictors. J Neurovirol. 2011; 17(1):3-16.

8. Jayadev S, Garden GA. Host and viral factors influencing the pathogenesis of HIV-associated neurocognitive disorders. J Neuroimmune Pharmacol. 2009;4(2):175-189.

9. Tozzi V, Balestra P, Galgani S, et al. Neurocognitive performance and quality of life in patients with HIV infection. AIDS Res Hum Retroviruses. 2003;19(8):643-652.

10. Gorman AA, Foley JM, Ettenhofer ML, Hinkin CH, van Gorp WG. Functional consequences of HIV-associated neuropsychological impairment. Neuropsychol Rev. 2009;19(2):186-203.

11. Hinkin CH, Castellon SA, Durvasula RS, et al. Medication adherence among HIV+ adults: effects of cognitive dysfunction and regimen complexity. Neurology. 2002;59(12):1944-1950.

12. Albert SM, Marder K, Dooneief G, et al. Neuropsychologic impairment in early HIV infection. A risk factor for work disability. Arch Neurol. 1995;52(5):525-530.

13. McCutchan JA, Marquie-Beck JA, Fitzsimons CA, et al. Role of obesity, metabolic variables, and diabetes in HIV-associated neurocognitive disorder. Neurology. 2012;78(7):485-492.

14. Clifford DB, Ances BM. HIV-associated neurocognitive disorder. Lancet Infect Dis. 2013;13(11):976-986.

15. Ancuta P, Kamat A, Kunstman KJ, et al. Microbial translocation is associated with increased monocyte activation and dementia in AIDS patients. PLoS One. 2008;3(6):e2516.

16. Edén A, Price RW, Spudich S, Fuchs D, Hagberg L, Gisslén M. Immune activation of the central nervous system is still present after $>4$ years of effective highly active antiretroviral therapy. $J$ Infect Dis. 2007;196(12):1779-1783.

17. Borjabad A, Volsky DJ. Common transcriptional signatures in brain tissue from patients with HIV-associated neurocognitive disorders, Alzheimer's disease, and Multiple Sclerosis. J Neuroimmune Pharmacol. 2012;7(4):914-926.

18. Robertson K, Liner J, Meeker RB. Antiretroviral neurotoxicity. J Neurovirol. 2012;18(5):388-399.

19. Ferris MJ, Mactutus CF, Booze RM. Neurotoxic profiles of HIV, psychostimulant drugs of abuse, and their concerted effect on the brain: current status of dopamine system vulnerability in NeuroAIDS. Neurosci Biobehav Rev. 2008;32(5):883-909.

20. Rodriguez-Penney AT, Iudicello JE, Riggs PK, et al. Co-morbidities in persons infected with HIV: increased burden with older age and negative effects on health-related quality of life. AIDS Patient Care STDS. 2013;27(1):5-16.

21. Gray LR, Roche M, Flynn JK, Wesselingh SL, Gorry PR, Churchill MJ. Is the central nervous system a reservoir of HIV-1? Curr Opin HIV AIDS. 2014;9(6):552-558.

22. Vago T, Clerici M, Norbiato G. Glucocorticoids and the immune system in AIDS. Bailliere Clin Endocrinol Metab. 1994;8(4):789-802.

23. Sapolsky RM, Romero LM, Munck AU. How do glucocorticoids influence stress responses? Integrating permissive, suppressive, stimulatory, and preparative actions. Endocr Rev. 2000;21(1):55-89.

24. Chaouloff F. Serotonin, stress and corticoids. J Psychopharmacol. 2000;14(2):139-151.

25. Young AH. The effects of HPA axis function on cognition and its implications for the pathophysiology of bipolar disorder. Harv Rev Psychiatry. 2014;22(6):331-333.

26. Frodl T, O'Keane V. How does the brain deal with cumulative stress? A review with focus on developmental stress, HPA axis function and hippocampal structure in humans. Neurobiol Dis. 2013;52:24-37.

27. Verges B, Chavanet P, Desgres J, et al. Adrenal function in HIV infected patients. Acta Endocrinol (Copenh). 1989;121(5):633-637. 
28. Biglino A, Limone P, Forno B, et al. Altered adrenocorticotropin and cortisol response to corticotropin-releasing hormone in HIV-1 infection. Eur J Endocrinol. 1995;133(2):173-179.

29. Lortholary O, Christeff N, Casassus P, et al. Hypothalamo-pituitaryadrenal function in human immunodeficiency virus-infected men.

30. Reif S, Mugavero M, Raper J, et al. Highly stressed: stressful and traumatic experiences among individuals with HIV/AIDS in the Deep South. AIDS Care. 2011;23(2):152-162.

31. Hand GA, Phillips KD, Dudgeon WD. Perceived stress in HIV-infected individuals: physiological and psychological correlates. AIDS Care. 2006;18(8):1011-1017.

32. George MM, Bhangoo A. Human immune deficiency virus (HIV) infection and the hypothalamic pituitary adrenal axis. Rev Endocr Metab Disord. 2013;14(2):105-112.

33. Costa A, Nappi RE, Polatti F, Poma A, Grossman AB, Nappi G. Stimulating effect of HIV-1 coat protein gp120 on corticotropin-releasing hormone and arginine vasopressin in the rat hypothalamus: involvement of nitric oxide. Exp Neurol. 2000;166(2):376-384.

34. Carpenter LL, Carvalho JP, Tyrka AR, et al. Decreased adrenocorticotropic hormone and cortisol responses to stress in healthy adults reporting significant childhood maltreatment. Biol Psychiatry. 2007;62(10):1080-1087.

35. Seck1 JR, Meaney MJ. Glucocorticoid “programming” and PTSD risk. Ann N Y Acad Sci. 2006;1071(1):351-378.

36. Heim C, Mletzko T, Purselle D, Musselman DL, Nemeroff CB. The dexamethasone/corticotropin-releasing factor test in men with major depression: role of childhood trauma. Biol Psychiatry. 2008;63(4):398-405.

37. de Kloet CS, Vermetten E, Geuze E, Kavelaars A, Heijnen CJ, Westenberg HG. Assessment of HPA-axis function in posttraumatic stress disorder: pharmacological and non-pharmacological challenge tests, a review. J Psychiatr Res. 2006;40(6):550-567.

38. Nugent NR, Amstadter AB, Koenen KC. Genetics of post-traumatic stress disorder: informing clinical conceptualizations and promoting future research. Am J Med Genet C Semin Med Genet. 2008;148C(2):127-132.

39. Tyrka AR, Price LH, Gelernter J, Schepker C, Anderson GM, Carpenter LL. Interaction of childhood maltreatment with the corticotropin-releasing hormone receptor gene: effects on hypothalamic-pituitary-adrenal axis reactivity. Biol Psychiatry. 2009;66(7):681-685.

40. Behan DP, Khongsaly O, Owens MJ, Chung HD, Nemeroff CB, De Souza EB. Corticotropin-releasing factor (CRF), CRF-binding protein (CRF-BP), and CRF/CRF-BP complex in Alzheimer's disease and control postmortem human brain. J Neurochem. 1997;68(5):2053-2060.

41. Liu Z, Zhu F, Wang G, et al. Association of corticotropin-releasing hormone receptor1 gene SNP and haplotype with major depression. Neurosci Lett. 2006;404(3):358-362.

42. Smoller JW, Yamaki LH, Fagerness JA, et al. The corticotropinreleasing hormone gene and behavioral inhibition in children at risk for panic disorder. Biol Psychiatry. 2005;57(12):1485-1492.

43. Bradley RG, Binder EB, Epstein MP, et al. Influence of child abuse on adult depression: moderation by the corticotropin-releasing hormone receptor gene. Arch Gen Psychiatry. 2008;65(2):190-200.

44. Roy A, Hodgkinson CA, Deluca V, Goldman D, Enoch MA. Two HPA axis genes, $C R H B P$ and $F K B P 5$, interact with childhood trauma to increase the risk for suicidal behavior. JPsychiatr Res. 2012;46(1):72-79.

45. Pratt WB, Toft DO. Steroid receptor interactions with heat shock protein and immunophilin chaperones. Endocr Rev. 1997;18(3):306-360. J Clin Endocrinol Metab. 1996;81(2):791-796.

46. Sheikh HI, Kryski KR, Smith HJ, Hayden EP, Singh SM. Corticotropinreleasing hormone system polymorphisms are associated with children's cortisol reactivity. Neuroscience. 2013;229:1-11.

47. Spies G, Fennema-Notestine C, Archibald SL, Cherner M, Seedat S. Neurocognitive deficits in HIV-infected women and victims of childhood trauma. AIDS Care. 2012;24(9):1126-1135.

48. Sheehan DV, Lecrubier Y, Sheehan KH, et al. The Mini-International Neuropsychiatric Interview (M.I.N.I.): the development and validation of a structured diagnostic psychiatric interview for DSM-IV and ICD-10. J Clin Psychiatry. 1998;59(Suppl 20):22-33.

49. Radloff LS. The CES-D Scale: A self-report depression scale for research in the general population. ApplPsychol Meas. 1977;1(3):385-401.

50. Davidson JR, Book SW, Colket JT, et al. Assessment of a new self-rating scale for post-traumatic stress disorder. Psychol Med. 1997;27(1):153-160.

51. Bernstein DP, Stein JA, Newcomb MD, et al. Development and validation of a brief screening version of the Childhood Trauma Questionnaire. Child Abuse Negl. 2003;27(2):169-190.

52. Spies G, Fennema-Notestine C, Cherner M, Seedat S. Changes in cognitive function in women with HIV infection and early life stress. AIDS Care. 2006;29(1):14-23.

53. Majer M, Nater UM, Lin JM, Capuron L, Reeves WC. Association of childhood trauma with cognitive function in healthy adults: a pilot study. BMC Neurol. 2010;10:61.

54. Barrett JC, Fry B, Maller J, Daly MJ. Haploview: analysis and visualization of LD and haplotype maps. Bioinformatics. 2005;21(2):263-265.

55. González JR, Armengol L, Solé X, et al. SNPassoc: an R package to perform whole genome association studies. Bioinformatics. 2007;23(5): 654-655.

56. Kallianpur AR, Levine AJ. Host genetic factors predisposing to HIVassociated neurocognitive disorder. Curr HIV/AIDS Rep. 2014;11(3): 336-352.

57. Levine AJ, Panos SE, Horvath S. Genetic, transcriptomic, and epigenetic studies of HIV-associated neurocognitive disorder. J Acquir Immune Defic Syndr. 2014;65(4):481-503.

58. de Luca V, Tharmalingam S, Kennedy JL. Association study between the corticotropin-releasing hormone receptor 2 gene and suicidality in bipolar disorder. Eur Psychiatry. 2007;22(5):282-287.

59. Enoch MA, Shen PH, Ducci F, et al. Common genetic origins for EEG, alcoholism and anxiety: the role of CRH-BP. PLoS One. 2008; 3(10):e3620.

60. Haass-Koffler CL, Henry AT, Melkus G, et al. Defining the role of corticotropin releasing factor binding protein in alcohol consumption. Transl Psychiatry. 2016;6(11):e953.

61. Binder EB, Owens MJ, Liu W, et al. Association of polymorphisms in genes regulating the corticotropin-releasing factor system with antidepressant treatment response. Arch Gen Psychiatry. 2010;67(4): 369-379.

62. O'Connell CP, Goldstein-Piekarski AN, Nemeroff CB, et al. Antidepressant outcomes predicted by genetic variation in corticotropin-releasing hormone binding protein. Am J Psychiatry. 2018;175(3):251-261.

63. Navalta CP, Polcari A, Webster DM, Boghossian A, Teicher MH. Effects of childhood sexual abuse on neuropsychological and cognitive function in college women. J Neuropsychiatry Clin Neurosci. 2006;18(1):45-53.

Neuropsychiatric Disease and Treatment

\section{Publish your work in this journal}

Neuropsychiatric Disease and Treatment is an international, peerreviewed journal of clinical therapeutics and pharmacology focusing on concise rapid reporting of clinical or pre-clinical studies on a range of neuropsychiatric and neurological disorders. This journal is indexed on PubMed Central, the 'PsycINFO' database and CAS,

\section{Dovepress}

and is the official journal of The International Neuropsychiatric Association (INA). The manuscript management system is completely online and includes a very quick and fair peer-review system, which is all easy to use. Visit http://www.dovepress.com/testimonials.php to read real quotes from published authors. 